\title{
Risiko Gangguan Perkembangan Neurologis antara Bayi Kurang Bulan Lanjut dan Bayi Cukup Bulan Sesuai Usia Kehamilan
}

\author{
Ike Dwi Wahyuni, Nelly Amalia Risan, Dwi Prasetyo \\ Departemen Ilmu Kesehatan Anak Fakultas Kedokteran Universitas Padjadjaran/Rumah Sakit Dr. Hasan Sadikin, Bandung
}

\begin{abstract}
Latar belakang. Bayi kurang bulan lanjut mempunyai fisiologis, metabolik, dan imunologi imatur, serta merupakan periode tercepat pertumbuhan dan perkembangan otak. Pada awal kehidupan, BKBL rentan mengalami komplikasi dan mempunyai risiko gangguan perkembangan neurologis (GPN).

Tujuan. Menentukan risiko GPN antara BKBL dan BCB sesuai usia kehamilan pada usia 3-6 bulan.

Metode. Penelitian dilaksanakan periode Oktober-Desember 2014 di RS Dr. Hasan Sadikin Bandung. Subjek penelitian adalah bayi BKBL usia 3-6 bulan dengan BCB sebagai kontrol yang memenuhi kriteria inklusi. Risiko GPN diperiksa menggunakan Bayley infant neurodevelopmental screener (BINS) dan dianalisis menggunakan uji chi-square dan rasio odds.

Hasil. Terdapat $36 \mathrm{BKBL}$ dan $36 \mathrm{BCB}$, dengan usia rerata 5,58 bulan pada BKBL dan 5,26 pada BCB. Perawakan pendek lebih banyak pada BKBL dibanding BCB. Sebagian besar subjek pada kedua kelompok tidak mendapatkan ASI eksklusif. Pendidikan terbanyak orangtua adalah SMP dan SMA dengan sebagian besar orangtua bekerja, tetapi mempunyai pendapatan/bulan yang rendah. Risiko GPN pada kelompok BKBL 22 dan BCB 10 bayi $(\mathrm{p}=0,004)$ dengan kekuatan hubungan risiko GPN pada BKBL 4,086 kali dibanding dengan $\mathrm{BCB}$ ( $\mathrm{RO}=4,086$; IK95\%:1,518-11,000).

Kesimpulan. Bayi kurang bulan lanjut sesuai usia kehamilan dan sesuai usia koreksi mempunyai risiko gangguan perkembangan neurologis 4,086 kali lebih besar dibanding dengan bayi cukup bulan. Sari Pediatri 2015;17(3):190-4.
\end{abstract}

Kata kunci: BINS, bayi cukup bulan (BCB), bayi kurang bulan lanjut (BKBL)

\section{The Risk for the Neurodevelopmental Delay between Late Preterm Infant and Term Infant Appropriate for Gestational Age}

\author{
Ike Dwi Wahyuni, Nelly Amalia Risan, Dwi Prasetyo
}

Background. Late preterm infants have physiological, metabolic and immunological immaturity, and it is the fastest period of brain growth and development, so LPTI are susceptible to complications and risk of neurodevelopmental delay (NDD).

Objective. To determine the association of risk of neurodevelopmental delay between LPTI and term infant (TI) at age 3-6 months.

Methods. The study conducted from October to December 2014 in Hasan Sadikin Hospital, Bandung. Subjects were LPTI, 3-6 months old of corrections age with TI was the control group who met the inclusion criteria. The risk of NDD was assessed using Bayley neurodevelopmental infant screener (BINS) and analyzed by chi-square and odds ratio test.

Results. The total number of subjects were 36 LPTI and 36 TI with mean age 5,58 and 5,26 months in LPTI and TI respectively. Short stature occured more on LPTI. Most of the subjects were not exclusively breasfed. Most parents had junior and senior high school education and were working, but had low income. The risk of NDD among LPTI was present in 22 LPTI and in $10 \mathrm{TI}$ and significantly associated $(\mathrm{p}=0.004)$ with the risk of NDD in LPTI 4,086 times greater than in TI $(\mathrm{RO}=4,086$ $\mathrm{IK}=1,518-11.000)$.

Conclusion. Late preterm infants with appropriate gestational age and corrected age were at risk of neurodevelopmental delay 4,086 times greater than term infants. Sari Pediatri 2015;17(3):190-4.

Keywords: BINS, developmental delay, late preterm infants, term infants

Alamat korespondensi: Dr. Ike Dwi Wahyuni. Departemen Ilmu Kesehatan Anak Fakultas Kedokteran Universitas Padjadjaran/Rumah Sakit Dr. Hasan Sadikin Bandung. Jl Pasteur No. 38 Bandung 40163, Indonesia. Tel. +62-22-3035957. E-mail: ikedwiwahyuni@yahoo.com 


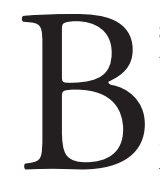
ayi kurang bulan lanjut (BKBL) merupakan bagian dari kelompok bayi kurang bulan (BKB), yaitu bayi yang lahir pada usia kehamilan 34 0/7-36 6/7 minggu. ${ }^{1,}$ ${ }^{2}$ Peningkatan insiden BKB di Amerika Serikat dari 9,1\% pada tahun 1981 menjadi 11,99\% pada tahun 2010 dengan 8,66\% bayi lahir pada periode kurang bulan lanjut. ${ }^{2-4}$ Bayi kurang bulan lanjut mempunyai mortalitas dan morbiditas yang tinggi karena fisiologi, metabolik, dan imunologi immatur sehingga rentan mengalami hipotermia, hipoglikemia, distres pernapasan, hiperbilirubinemia, dan infeksi pada awal kehidupan. Pertumbuhan dan perkembangan otak pada BKBL belum sempurna, berat otak baru mencapai $60 \%$, volume otak $50 \%$, dan $25 \%$ perkembangan serebelum terjadi dalam periode ini. Empat minggu terakhir kehamilan terjadi pertumbuhan yang sangat pesat girus, sulkus, sinaps, dendrit, akson, oligodendrosit, astrosit, dan mikroglia. Morbiditas yang terjadi pada periode ini dapat mengganggu metabolisme sel otak dan proses premielinisasi sehingga berisiko mengalami gangguan perkembangan neurologis. ${ }^{2,5-7}$

Di Amerika Serikat, gangguan perkembangan neurologis BKBL adalah 36\%. Di negara berkembang, perkiraan risiko gangguan perkembangan neurologis pada BKBL lebih tinggi dibanding dengan negara maju karena pengaruh faktor risiko biologis dan lingkungan. ${ }^{3}$ Bayi kurang bulan lanjut mempunyai ukuran yang cukup besar dan penampilan seperti bayi matur sehingga dirawat oleh orangtua atau pengasuh seperti bayi matur yang mempunyai risiko rendah. ${ }^{1}$

Gangguan perkembangan neurologis pada BKBL belum banyak diteliti, khususnya pada usia $<1$ tahun. Penelitian Woythaler $\mathrm{dkk}^{8}{ }^{8}$ pada anak usia 24 bulan dengan riwayat $\mathrm{BKBL}$ dan $\mathrm{BCB}$, didapatkan skor mental developmental index (MDI) 85 dan 89, dan skor psychomotor developmental index (PDI) 88 dan 92 $(\mathrm{p}<0,0001)$. Sementara itu, Setyorini dkk ${ }^{9}$ mendapatkan perkembangan kognitif yang lebih rendah pada BKBL dibanding dengan $\mathrm{BCB}$ yang dilakukan pada usia 3 bulan dengan mullen scales of early listening (MSEL). Soysal $\mathrm{dkk}^{10}$ menilai skor verbal menggunakan BINS pada anak usia 7-10 bulan dan 16-20 bulan dengan riwayat kelahiran BBLR mendapatkan prediksi yang baik terhadap skor verbal dan performance sehingga intervensi dapat segera dimulai.

Belum ada penelitian gangguan perkembangan neurologis pada BKBL saat usia 3-6 bulan sehingga perlu dilakukan skrining gangguan perkembangan neurologis sejak usia dini (3-6 bulan) untuk memperbaiki kualitas hidup bayi di kemudian hari. Tujuan penelitian ini adalah Menentukan hubungan risiko gangguan perkembangan neurologis antara BKBL dan BCB pada usia 3-6 bulan.

\section{Metode}

Penelitian dilakukan di RS Dr. Hasan Sadikin dan RSIA Kota Bandung pada bulan Oktober-Desember 2014. Subjek penelitian adalah BKBL, sesuai usia kehamilan, berusia 3-6 bulan, sesuai usia koreksi dan BCB sebagai kontrol, lahir di RS Dr. Hasan Sadikin dan RSIA Kota Bandung. Subjek dieksklusi bila memiliki kelainan kongenital berat, kelainan jantung berat, malnutrisi berat, saat pemeriksaan sedang menderita penyakit infeksi akut, mempunyai riwayat asfiksia, HIE grade III, sepsis berat, meningitis, neonatal hiperbilirubinemia dengan indikasi transfusi ganti, bilirubin ensefalopati, neonatal seizure, dan perdarahan intrakranial. Jumlah subjek penelitian ditentukan berdasarkan perhitungan sampel uji beda, yaitu masing-masing 36 bayi.

Setelah orangtua subjek diberikan sosialisasi tentang penelitian dan menandatangani persetujuannya (informed consent), subjek yang memenuhi kriteria inklusi dilakukan pencatatan identitas, penelusuran riwayat kelahiran melalui rekam medis kelahiran, pemeriksaan antropometris, dan BINS yang dilakukan oleh dokter yang telah menjalani uji kesesuaian dengan nilai kappa 1. Karakteristik subjek dan orang tua disajikan secara deskriptif. Hubungan risiko gangguan perkembangan neurologis antara $\mathrm{BKBL}$ dan $\mathrm{BCB}$ dianalisis menggunakan uji chi-square dan kekuatan hubungan dianalisis menggunakan uji rasio Odds pada interval kepercayaan IK95\%. Penelitian ini telah disetujui oleh Komite Etik Penelitian Fakultas Kedokteran Universitas Padjadjaran/RS Dr. Hasan Sadikin, Bandung.

\section{Hasil}

Karakteristik subjek penelitian antara BKBL dan BCB didapatkan subjek penelitian terdiri atas 34 bayi laki-laki dan 38 perempuan dengan usia rerata 5,58 bulan pada kelompok BKBL dan 5,26 bulan pada 
kelompok BCB. Perawakan pendek pada BKBL lebih banyak dibanding dengan $\mathrm{BCB}$ dan sebagian besar subjek pada kedua kelompok tidak mendapatkan ASI eksklusif (Tabel 1).

Tabel 1. Karakteristik subjek penelitian

\begin{tabular}{lcc}
\hline Variabel & $\begin{array}{c}\mathrm{BKBL} \\
\mathrm{n}=36\end{array}$ & $\begin{array}{c}\mathrm{BCB} \\
\mathrm{n}=36\end{array}$ \\
\hline Jenis kelamin & & \\
$\quad$ Laki-laki & 17 & 17 \\
$\quad$ Perempuan & 19 & 19 \\
Usia (bulan) & & \\
$\quad$ Rerata (SB) & $5,58(0,61)^{*}$ & $5,26(0,77)^{*}$ \\
$\quad$ Rentang & $4,33-6,67$ & $3,07-6,67$ \\
Perawakan pendek & & \\
$\quad$ Ya & 14 & 9 \\
$\quad$ Tidak & 22 & 27 \\
Berat badan kurang & & 2 \\
$\quad$ Ya & 2 & 34 \\
$\quad$ Tidak & 34 & \\
Mikrosefal & & 5 \\
$\quad$ Ya & 6 & \\
$\quad$ Tidak & 30 & 14 \\
ASI eksklusif & & 22 \\
$\quad$ Ya & 12 & \\
Tidak & 24 &
\end{tabular}

Keterangan: BKBL: bayi kurang bulan lanjut, BCB: bayi cukup bulan, *SB: simpang baku

Karakteristik subjek penelitian antara BKBL dan $\mathrm{BCB}$ adalah jenis kelamin, usia, perawakan pendek, berat badan kurang, mikrosefal, dan ASI eksklusif. Subjek terdiri atas 36 BKBL dan 36 BCB, setiap kelompok terdiri atas 17 anak laki-laki dan 19 perempuan. Usia rerata kelompok BKBL 5,58 dan kelompok BCB 5,26 bulan. Perawakan pendek didapatkan lebih banyak pada kelompok BKBL (14/36) dibanding dengan BCB (9/36). Berat badan kurang dan mikrosefal hampir sama pada kedua kelompok. Sebagian besar subjek pada kedua kelompok tidak mendapatkan ASI eksklusif, yaitu 24/36 pada
BKBL dan 22/36 pada BCB.

Karakteristik orangtua subjek antara BKBL dan $\mathrm{BCB}$ adalah usia, pendidikan, dan pekerjaan orangtua, serta penghasilan keluarga/bulan. Usia rerata ibu pada kelompok BKBL adalah 26,72 tahun dan BCB adalah 28,14 tahun. Sementara usia rerata ayah pada kelompok BKBL dan BCB adalah 29,00 dan 30,43 tahun. Pendidikan orangtua pada kedua kelompok

Tabel 2. Karakteristik orang tua

\begin{tabular}{|c|c|c|}
\hline Variabel & $\begin{array}{c}\text { BKBL } \\
n=36\end{array}$ & $\begin{array}{l}\text { BCB } \\
n=36\end{array}$ \\
\hline \multicolumn{3}{|l|}{ Ibu } \\
\hline \multicolumn{3}{|l|}{ Usia (tahun) } \\
\hline Rerata $(\mathrm{SB})^{*}$ & $26,72(5,83)^{*}$ & $28,14(6,05)^{*}$ \\
\hline Rentang & $16-39$ & $17-42$ \\
\hline \multicolumn{3}{|l|}{ Pendidikan } \\
\hline Tidak sekolah-SD & 0 & 3 \\
\hline SMP-SMA & 26 & 19 \\
\hline D1-Sarjana & 10 & 14 \\
\hline \multicolumn{3}{|l|}{ Pekerjaan } \\
\hline Bekerja & 23 & 30 \\
\hline Tidak bekerja & 13 & 6 \\
\hline \multicolumn{3}{|l|}{ Ayah } \\
\hline \multicolumn{3}{|l|}{ Usia (tahun) } \\
\hline Rerata $(\mathrm{SB})^{*}$ & $29,00(5,38)^{*}$ & $30,43(6,81)^{*}$ \\
\hline Rentang & $17-43$ & $19-42$ \\
\hline \multicolumn{3}{|l|}{ Pendidikan } \\
\hline Tidak sekolah-SD & 3 & 2 \\
\hline SMP-SMA & 25 & 21 \\
\hline D1-Sarjana & 8 & 13 \\
\hline \multicolumn{3}{|l|}{ Pekerjaan } \\
\hline Bekerja & 35 & 34 \\
\hline Tidak bekerja & 1 & 2 \\
\hline \multicolumn{3}{|c|}{ Penghasilan keluarga/bulan/juta } \\
\hline $0-<2$ & 20 & 15 \\
\hline $2-\leq 5$ & 16 & 13 \\
\hline$>5$ & 0 & 8 \\
\hline
\end{tabular}

BKBL: Bayi kurang bulan lanjut, BCB: bayi cukup bulan. ${ }^{*}$ SB: simpang baku

Tabel 3. Analisis bivariat risiko gangguan perkembangan neurologis antara BKBL dan BCB

\begin{tabular}{lcccc}
\hline & \multicolumn{2}{c}{ Risiko gangguan perkembangan neurologis } & \multirow{2}{*}{ Nilai $\mathrm{p}$} & \multirow{2}{*}{ RO (IK=95\%) } \\
\cline { 2 - 3 } & $(+)$ & $(-)$ & & \\
\cline { 2 - 3 } BKBL & 22 & 10 & 0,004 & $4,086(1,518-11,000)$ \\
BCB & 14 & 26 & & \\
\hline
\end{tabular}

Keterangan: BKBL: bayi kurang bulan lanjut, BCB: bayi cukup bulan, GPN: gangguan perkembangan neurologis, RO: rasio Odds, IK: interval kepercayaan. Nilai p dihitung berdasarkan uji chi-square. 
paling banyak adalah SMP dan SMA. Ayah dan ibu subjek pada kedua kelompok sebagian besar bekerja dan sebagian besar berpenghasilan rendah $(<\mathrm{Rp}$. 2.000.000,-/bulan).

Hubungan risiko gangguan perkembangan neurologis antara BKBL dan BCB didapatkan hubung bermakna $(\mathrm{p}=0,004)$. Kekuatan hubungan dianalisis dengan uji rasio Odds, dan didapatkan $\mathrm{RO}=4,086$ $(\mathrm{IK} 95 \%=1,518-11,000)$.

\section{Pembahasan}

Usia kehamilan 34-36 minggu merupakan periode kritis pertumbuhan dan perkembangan otak janin karena pada periode ini otak janin tumbuh dan berkembang paling cepat. Berat otak baru mencapai $60 \%$ dari BCB dengan girus dan sulkus yang belum sempurna. Volume otak mengalami peningkatan $50 \%$ pada usia kehamilan 34 sampai 40 minggu, 25\% perkembangan serebelum terjadi dalam periode ini, dan terjadi pertumbuhan yang sangat pesat girus, sulkus, sinaps, dendrit, akson, oligodendrosit, astrosit, dan mikroglia sehingga mielinisasi belum berkembang secara nyata. Bayi kurang bulan lanjut juga mempunyai fisiologis, metabolik, dan imunologis imatur, sehingga rentan mengalami komplikasi. Dengan demikian, morbiditas yang terjadi pada periode ini akan mengganggu metabolisme sel otak, kematian oligodendrosit, dan akan menggangu proses premielinisasi, sehingga BKBL berisiko lebih besar mengalami gangguan perkembangan neurologis., 5-7, 11

Hasil penelitian kami menunjukkan risiko gangguan perkembangan neurologis pada BKBL dan $\mathrm{BCB}$ sesuai usia kehamilan dan sesuai usia koreksi pada usia 3-6 bulan. Bayi kurang bulan lanjut pada penelitian kami mempunyai risiko gangguan perkembangan neurologis 4,086 kali lebih besar dibandingkan BCB.

Hal tersebut telah dilaporkan pada penelitian terdahulu, yaitu penelitian kohort prospektif yang dilakukan oleh Woythaler $\mathrm{dkk}^{8}$ pada BKBL dan BCB berusia 24 bulan dengan didapatkan skor mental developmental index (MDI) 85 dan 89, dan skor psychomotor developmental index (PDI) 88 dan 92. Penelitian Setyorini $\mathrm{dkk}^{9}$ dengan metode kohort prospektif terhadap BKBL mendapatkan perkembangan kognitif yang lebih rendah pada BKBL dibanding dengan $\mathrm{BCB}$ yang dilakukan pada usia 3 bulan dengan Mullen scale's of early listening (MSEL).
Risiko gangguan perkembangan neurologis BKBL di negara berkembang, termasuk Indonesia diperkirakan lebih besar karena dipengaruhi oleh faktor lingkungan dan biologis, seperti kemiskinan, pola asuh, dan pengetahuan orangtua serta nutrisi. ${ }^{3}$ Air susu ibu eksklusif, pendidikan, dan pendapatan keluarga yang rendah, serta perawakan pendek pada penelitian ini kemungkinan menjadi faktor risiko GPN. Namun, hal tersebut tidak dapat diperhitungkan, mengingat jumlah sampel yang tidak mencukupi. ${ }^{12,13}$

Keterbatasan penelitian ini adalah keterbatasan waktu penelitian sehingga tidak dapat dilakukan pengambilan subjek dalam jumlah besar untuk mencari faktor risiko lain gangguan perkembangan neurologis pada BKBL maupun BCB.

\section{Kesimpulan}

Bayi kurang bulan lanjut sesuai usia kehamilan dan sesuai usia koreksi berhubungan dengan risiko gangguan perkembangan neurologis lebih besar dibanding dengan bayi cukup bulan.

\section{Daftar pustaka}

1. Engle WA, Tomashek KM, Wallman C. "Late-preterm" infants: a population at risk. Pediatrics 2007;120:1390401.

2. Raju TNK, Stark RDHR, Leveno KJ. Optimizing care and outcome for late-preterm (near-term) infants: a summary of the workshop sponsored by the National Institute of Child Health and Human Development. Pediatrics 2006;118:1207-14.

3. Dong Y, Yu J-L. An overview of morbidity, mortality and long-term outcome of late preterm birth. World J Pediatr 2011;7:199-204.

4. Martin JA, Hamilton BE, Ventura SJ, Osterman MJK, Wilson EC, Mathews TJ. Births: final data for 2010. National Vital Statistics Reports 2012;6:1-72.

5. Engle WA, Kominiarek MA. Late preterm infants, early term infants, and timing of elective deliveries. Clin Perinatol 2008;35:325-41.

6. Kinney HC. The near-term (late preterm) human brain and risk for periventricular leukomalacia: a review. Semin Perinatol 2006;30:81-8.

7. Loftin RW, Habli M, Snyder CC, Cormier MC, Lewis 
DF, DeFranco EA. Late preterm birth. MedReviews 2010;3:10-9.

8. Woythaler MA, McCormick MC, Smith VC. Late preterm infants have worse 24-month neurodevelopmental outcomes than term infants. Pediatrics 2011;127:622-9.

9. Setyorini A, Soetjiningsih, Haksari EL. Cognitive outcome in late preterm babies. Paediatr Indones 2010;50:239-44.

10. Soysal AS, Gucuyener K, Ergenekon E, Turan Ö, Koc E, Turkyılmaz C, dkk. The prediction of later neurodevelopmental status of preterm infants at ages 7 to 10 years using the Bayley infant neurodevelopmental screene. J Child Neurol 2014;27:1621-2.

11. Saher G, Brugger B, Lappe-Siefke C, Mobius W, Tozawa R, Wehr M, dkk. High cholesterol level is essential for myelin membrane growth. Nat Neurosci 2005;8:46875.

12. Isaacs E, Fischl B, Quinn B, Chong W, Gadian D, Lucas A. Impact of breast milk on intelligence quotient, brain size, and white matter development. Pediatr Res 2010;67:357-62.

13. Santos IS, Matijasevich A, Domingues MR, Barros AJ, Victor CG, Barros FC. Late preterm birth is a risk factor for growth faltering in early childhood: a cohort study. BMC 2009;9:1-8. 